\title{
PENGARUH KOMPOSISI MEDIA SAPIH DAN DOSIS PUPUK NPK TERHADAP PERTUMBUHAN BIBIT MAHONI (Swietenia macrophylla King) DI PERSEMAIAN
}

\author{
(Effects of the Composition Media and NPK Fertilizer Dosage on the Growth of Mahogani
} (Swietenia macrophylla King) Seedlings in the Nursery)

\author{
Abdul Hakim Lukman \\ Balai Penelitian Kehutanan Palembang \\ Jl. Kol. H. Burlian Km 6,5, Punti Kayu, Palembang, Telp. (0711) 414864
}

Naskah masuk : 10 Februari 2011; Naskah diterima : 1 Februari 2012

\begin{abstract}
The aim of the experiment was to examine effects of the composition media and NPK fertilizer dosage to the growth of mahagony (Swietenia macrophylla) seedlings in the nursery. This experiment was conducted in the nursery of the Forest Research Institute Palembang. The research design used was a factorial experiment which was laid out in randomized completely block design. Seedling growing media used were top soil 100\%, mixture of top soil and saw dust compost in varying rates (70:30, 60:40 and 50:50). NPK fertilizer was applied at varying rates $0 ; 0.5 ; 1.0$; and $1.5 \mathrm{~g} /$ seedling. Seedling height, diameter and quality index were used as variables of seedling growth. The results revealed that seedling growing medium, rate of NPK fertilizer and their interaction significantly affect seedling height and diameter. Mixture of top soil and saw dust compost at 50:50 and applied with NPK $1 \mathrm{~g} / \mathrm{seedling}$ is the best media producing seedling height, diameter, and quality index of $12.22 \mathrm{~cm}, 2.19 \mathrm{~mm}$ and 0.13 respectively.
\end{abstract}

Keywords: Seedlings, composting media, mahogani (Swietenia macrophylla King), NPK fertilizer

\begin{abstract}
ABSTRAK
Tujuan dari penelitian ini adalah untuk menguji efek dari media dan dosis pupuk NPK terhadap pertumbuhan bibit mahoni (Swietenia macrophylla) di persemaian. Penelitian dilakukan di persemaian Balai Penelitian Kehutanan Palembang. Rancangan yang digunakan adalah Rancangan penelitian faktorial dalam rancangan acak lengkap berblok. Perlakuan media terdiri dari 4 (empat) taraf yaitu media tanah 100\%, dan campuran tanah dengan kompos serbuk gergaji dengan perbandingan 70:30, 60:40 dan 50:50; sedangkan faktor dosis pupuk NPK terdiri dari 4 (empat) taraf, yaitu 0, 1,5, 1,0 dan 1,5 g/bibit. Peubah yang diamati adalah pertambahan tinggi dan diameter serta indeks kualitas semai. Hasil penelitian menunjukkan bahwa interaksi antara faktor media sapih dan dosis pupuk NPK mempengaruhi secara nyata terhadap pertambahan tinggi dan diameter bibit mahoni, tetapi tidak mempengaruhi terhadap nilai indeks kualitas semai. Kombinasi perlakuan yang terbaik dan efisien dalam penggunaan pupuk NPK adalah media campuran tanah dan kompos serbuk gergaji pada perbandingan 50:50 dengan dosis pupuk NPK $1 \mathrm{~g} / \mathrm{bibit}$. Perlakuan ini menghasilkan bibit dengan nilai pertambahan tinggi dan diameter serta indeks kualitas semai berturut-turut $12,22 \mathrm{~cm}, 2,19 \mathrm{~mm}$ dan 0,13 .
\end{abstract}

\section{Kata kunci : Bibit, komposisi media, mahoni (Swietenia macrophylla King), pupuk NPK}

\section{PENDAHULUAN}

Kebutuhan kayu pertukangan sampai saat ini sebagian besar masih dipenuhi dari hutan alam. Dengan kecepatan pemanenan yang jauh lebih tinggi dari pada kecepatan pemulihan kembali hutan alam, produksi kayu dari hutan alam makin menurun, baik dari segi jumlah maupun mutunya. Untuk memenuhi kebutuhan kayu pertukangan yang tinggi, diperlukan upaya penanaman baik dalam bentuk rehabilitasi hutan alam maupun pembangunan hutan tanaman.

Agar upaya penanaman tersebut berhasil maka di samping pemilihan jenis pohon yang 
sesuai dengan kondisi lingkungan setempat, penggunaan bibit yang bermutu perlu pula dilakukan, sehingga pertumbuhan tanaman atau tegakan yang dibangun tumbuh optimal. Mahoni adalah salah satu jenis pohon yang dapat digunakan untuk reboisasi lahan kritis, rehabilitasi hutan produksi dan pembangunan hutan tanaman industri. Sementara untuk memperoleh bibit yang bermutu dapat ditempuh melalui penggunaan benih yang bermutu maupun pemeliharaan yang intensif dalam pembibitannya.

Pembibitan tanaman hutan pada umumnya masih menggunakan media sapih tanah lapisan olah, walaupun beberapa perusahaan Hutan Tanaman Industri (HTI) sudah menggunakan media sapih non-tanah. Penggunaan tanah lapisan olah untuk media pertumbuhan bibit mempunyai beberapa kelemahan diantaranya adalah media sapih cepat padat, aerasi kurang baik, berat per satuan bibit tinggi dan ketersediaan unsur hara tertentu bagi tanaman kurang. Adanya alternatif bahan pencampur atau bahan pengganti media sapih tanah yang mempunyai sifat lebih baik bagi pertumbuhan bibit tanaman kehutanan sangat diperlukan. Selain penggunaan media sapih yang baik, untuk memacu pertumbuhan bibit dipersemaian diperlukan pemberian pupuk seperti NPK pada taraf dosis tertentu.

Tujuan penelitian ini adalah mempelajari pengaruh komposisi media sapih campuran tanah dengan kompos serbuk gergaji dan dosis pupuk NPK terhadap pertumbuhan bibit mahoni. Diharapkan dari kajian ini diperoleh komposisi media sapih campuran tanah dengan kompos serbuk gergaji yang optimal, dan dosis pupuk NPK yang tepat, yang dapat menunjang program pengembangan hutan tanaman.

\section{BAHAN DAN METODE}

\section{A. Bahan dan Alat}

Bahan yang digunakan antara lain adalah benih mahoni ( $S$. macrophylla), pupuk NPK 15:15:15, tanah, kompos serbuk gergaji, bak tabur, dan polybag, sedangkan peralatan yang digunakan antara lain hand sprayer, gembor, mistar dan kaliper.

\section{B. Metode Penelitian}

\section{Rancangan Percobaan}

Perlakuan yang diujicobakan terdiri dari dua faktor yaitu komposisi media sapih dan dosis pupuk NPK masing-masing dengan empat taraf perlakuan. Faktor media sapih terdiri dari media tanah $100 \%$, campuran tanah dan kompos serbuk gergaji $70: 30,60: 40$, dan $50: 50$. Sedangkan taraf faktor dosis NPK adalah tanpa pupuk (0 g/batang); 0,5 g/batang; 1,0 g/batang; dan 1,5 $\mathrm{g} /$ batang. Percobaan disusun dalam pola Rancangan Acak Lengkap Kelompok Faktorial dengan jumlah kelompok sebanyak tiga buah sebagai ulangan.

\section{Tahapan Kegiatan}

Benih mahoni disemai dalam bak tabur yang berisi media pasir halus dan dilakukan penyiraman dua kali sehari. Setelah berkecambah, semai kemudian disapih ke dalam polibag yang telah diisi dengan media sapih yang sesuai dengan perlakuan yang telah ditentukan. Pencampuran media sapih tanah dan kompos serbuk gergaji dilakukan berdasarkan perbandingan volume.

Bibit yang telah disapih kemudian disusun dalam bedengan sesuai dengan perlakuan dan rancangan percobaan yang digunakan. Bedeng sapih diberi naungan dengan menggunakan paranet dengan intensitas cahaya 65\%. Dua minggu setelah penyapihan dilakukan aplikasi perlakuan pemupukan NPK 15:15:15 sesuai perlakuan dosis yang telah ditentukan. Penyiraman dilakukan setiap hari dengan frekuensi 1 - 2 kali tergantung dari keadaan cuaca.

\section{Peubah yang diamati}

Peubah yang diamati setelah bibit berumur empat bulan adalah pertambahan tinggi, pertambahan diameter batang dan indeks kualitas semai (IKS).

\section{Metode Penelitian}

Data hasil pengamatan diolah dan dianalisis dengan menggunakan sidik ragam (analisis varian), kemudian apabila hasil analisis ragam pada suatu peubah menunjukkan perbedaan yang nyata, pengujian dilanjutkan dengan menggunakan uji Beda Nyata Jujur (BNJ).

\section{HASIL DAN PEMBAHASAN}

\section{A. Hasil}

Hasil analisis ragam (Tabel 1.) menunjukkan bahwa faktor media dan dosis pupuk NPK serta interaksi antara kedua faktor tersebut 
masing-masing memberikan pengaruh yang sangat nyata terhadap kedua peubah yang diamati, kecuali terhadap Indeks Kualitas Semai (IKS). Untuk mengetahui interaksi antara media sapih dan dosis pupuk yang berpengaruh terhadap peubah pertambahan tinggi dan pertambahan diameter dilakukan uji BNJ (Tabel 2).

Berdasarkan hasil pada Tabel 2 terlihat bahwa pertambahan tinggi dan diameter bibit mahoni berturut-turut berkisar antara $8,30 \mathrm{~cm}$ $13,30 \mathrm{~cm}$ dan $1,30 \mathrm{~mm}-2,20 \mathrm{~mm}$. Pertambahan tinggi dan diameter bibit mahoni makin besar dengan bertambahnya komposisi kompos serbuk gergaji, baik pada dosis pupuk NPK $1 \mathrm{~g}$ /batang maupun 1,5 g/batang.

Penggunaan media tanah $100 \%$ menghasilkan pertambahan tinggi dan diameter batang yang lebih rendah pada semua tingkat dosis pupuk yang diuji. Aplikasi pupuk NPK cenderung memberikan nilai pertumbuhan bibit yang makin meningkat dengan meningkatnya dosis pupuk NPK yang diberikan. Pola hubungan linier antara dosis pupuk NPK dengan pertumbuhan tinggi dan diameter dapat terlihat pada Tabel 1, artinya makin tinggi dosis pupuk NPK yang diaplikasikan akan memberikan pertumbuhan tinggi dan diameter yang lebih besar.

Tabel(Table) 1. Analisis ragam untuk pertambahan tinggi dan diameter serta nilai indeks kualitas semai bibit mahoni pada umur 4 bulan (Analysis of variance for height, diameter and quality index of mahagony seedlings at 4 months age)

\begin{tabular}{|c|c|c|c|}
\hline \multirow[b]{2}{*}{$\begin{array}{l}\text { Sumber Keragaman } \\
\text { (Source of Variance) }\end{array}$} & \multicolumn{3}{|c|}{ Kuadrat Tengah (Mean Square) } \\
\hline & $\begin{array}{c}\text { Pertambahan } \\
\text { Tinggi } \\
\text { (Height Increment) }\end{array}$ & $\begin{array}{c}\text { Pertambahan } \\
\text { Diameter } \\
\text { (Diameter Increment) }\end{array}$ & $\begin{array}{c}\text { Indeks } \\
\text { Kualitas Semai } \\
\text { (Seedling Quality Index) }\end{array}$ \\
\hline Kelompok (Block) & $1,0745^{* *}$ & $0,0146^{\mathrm{ns}}$ & $0,0029^{\mathrm{ns}}$ \\
\hline Media (Media) & $14,5671^{* *}$ & $0,8180^{* *}$ & $0,0044^{\mathrm{ns}}$ \\
\hline Pupuk (Fertilizer) & $4,2488^{* *}$ & $0,3034^{* *}$ & $0,0018^{\mathrm{ns}}$ \\
\hline - Linier (Linear) & $10,5840^{* *}$ & $0,8628^{* *}$ & $0,0022^{\mathrm{ns}}$ \\
\hline - Kuadratik (Quadratic) & $0,2002^{\mathrm{ns}}$ & $0,0426^{\mathrm{ns}}$ & $0,0026^{\mathrm{ns}}$ \\
\hline - Kubik (Cubic) & $1,9620^{\mathrm{ns}}$ & $0,0048^{\mathrm{ns}}$ & $0,0007^{\mathrm{ns}}$ \\
\hline $\begin{array}{l}\text { Media*Pupuk } \\
\text { (Media*Fertilizer) }\end{array}$ & $1,5198^{* *}$ & $0,0102^{* *}$ & $0,0006^{\mathrm{ns}}$ \\
\hline Galat (Error) & 0,2085 & 0,0012 & 0,0180 \\
\hline
\end{tabular}

Tabel (Table) 2. Pengaruh interaksi antara media sapih dan dosis pupuk terhadap pertambahan tinggi dan diameter bibit mahoni umur 4 bulan (Effects of interaction between media and fertilizer dose on the height and diameter increment of mahagony seedlings at 4-month age)

\begin{tabular}{|c|c|c|c|c|}
\hline \multirow{2}{*}{$\begin{array}{c}\text { Dosis pupuk NPK, g/btg } \\
\text { (NPK Fertilizer Dose, } \\
\text { g/seedling) }\end{array}$} & \multicolumn{4}{|c|}{$\begin{array}{l}\text { Tanah : kompos serbuk gergaji } \\
\text { (Soil : Saw dust compost })\end{array}$} \\
\hline & $100: 0$ & $70: 30$ & $60: 40$ & $50: 50$ \\
\hline & \multicolumn{4}{|c|}{ Pertambahan tinggi (Height increment), $\mathrm{cm}$} \\
\hline 0 & $8,30 \mathrm{~b} \mathrm{C}$ & 10,45 a B & $11,30 \mathrm{~b} A$ & $10,30 \mathrm{c} \mathrm{B}$ \\
\hline 0,5 & $8,58 \mathrm{~b} \mathrm{C}$ & 10,27 a B & $11,02 \mathrm{~b} \mathrm{~A}$ & $10,20 \mathrm{c} \mathrm{B}$ \\
\hline 1,0 & 9,45 a $\mathrm{D}$ & 10,80 a C & $11,45 \mathrm{a} \mathrm{E}$ & $12,22 \mathrm{~b} \mathrm{~A}$ \\
\hline \multirow[t]{2}{*}{1,5} & 9,70 a C & 10,87 a B & $10,78 \mathrm{~b} \mathrm{E}$ & 13,31 a A \\
\hline & \multicolumn{4}{|c|}{ Pertambahan diameter (Diameter increment), $\mathrm{mm}$} \\
\hline 0 & $1,30 \mathrm{c} \mathrm{C}$ & $1,86 \mathrm{~b} \mathrm{~A}$ & $1,82 \mathrm{c} \mathrm{A}$ & $1,74 \mathrm{c} \mathrm{B}$ \\
\hline 0,5 & $1,48 \mathrm{~b} \mathrm{C}$ & $1,91 \mathrm{~b} \mathrm{~B}$ & $1,97 \mathrm{~b} \mathrm{~A}$ & $2,01 \mathrm{~b} \mathrm{~A}$ \\
\hline 1,0 & $1,52 \mathrm{~b} \mathrm{C}$ & 2,11 a B & 2,14 a B & 2,19 a A \\
\hline 1,5 & 1,69 a $\mathrm{C}$ & 2,11 a $\mathrm{B}$ & 2,13 a B & 2,20 a $\mathrm{A}$ \\
\hline
\end{tabular}

Keterangan (Remarks) : Angka pada kolom yang sama yang dikuti huruf kecil yang sama tidak berbeda nyata pada taraf $5 \%$ berdasarkan uji BNJ (Figures in the same column followed by the same small letter are not significantly different at $5 \%$ level according to HSD test). Angka pada baris yang sama yang dikuti huruf kapital yang sama tidak berbeda nyata pada taraf $5 \%$ berdasarkan uji BNJ (Figures in the same row followed by the same capital letter are not significantly different at $5 \%$ level according to HSD test) 
Kombinasi perlakuan media sapih campuran tanah dan kompos serbuk gergaji (50:50) dengan dosis pupuk NPK 1,5 g/batang, merupakan perlakuan yang baik, dengan menghasilkan nilai pertambahan tinggi dan pertambahan diameter berturut-turut sebesar $13,31 \mathrm{~cm}$ dan 2,20 $\mathrm{mm}$. Hal ini menunjukkan bahwa perlakuan tersebut dapat meningkatkan pertambahan tinggi dan diameter batang bibit mahoni masing-masing sebesar $60,36 \%$ dan $69,23 \%$ dibanding kontrol.

\section{B. Pembahasan}

Penggunaan media sapih campuran tanah dan kompos serbuk gergaji dalam pembibitan mahoni daun lebar dapat memberikan pertumbuhan bibit yang lebih baik dibanding dengan menggunakan media tanah $100 \%$. Hal ini mengindikasikan bahwa pemanfaatan kompos serbuk gergaji sebagai bahan campuran untuk media sapih pada tanaman mahoni adalah sangat bagus. Hal ini senada dengan Montano (1977) dalam Hendromono (1987) yang menyatakan bahwa kompos serbuk gergaji sangat baik digunakan untuk media sapih karena mempunyai kemampuan menahan dan melepaskan hara yang lebih baik dari pada media tanah, meskipun kandungan hara mineralnya rendah. Selain itu kompos serbuk gergaji memiliki kemampuan menahan air tinggi, aerasi yang bagus, dan jauh lebih ringan (Widiarti, 1995).

Pemanfaatan campuran serbuk gergaji dengan tanah pada pembibitan beberapa jenis tanaman (kehutanan) seperti yang telah dilaporkan oleh beberapa penulis mempunyai perbandingan komposisi yang berbeda. Widiarti (1995), melaporkan pertumbuhan dan perkembangan bibit tanaman cendana terbaik adalah dengan menggunakan media campuran tanah dan serbuk gergaji pada komposisi 50:50, sedangkan pada bibit Shorea selanica dan Shorea leprosula, komposisi campuran yang terbaik masingmasing adalah 60:40 dan 80:20 (Heriyanto dan Masano, 1997). Tanaman mahoni juga mempunyai karakteristik jenis tersebut, yaitu pertumbuhan dan perkembangan bibitnya sangat baik pada media sapih dengan komposisi 50:50, sedangkan pada komposisi serbuk gergaji yang lebih rendah (30 dan $40 \%$ ) pertumbuhan bibit mahoni cenderung lebih rendah.

Perbandingan komposisi media sapih antara tanah dan kompos serbuk gergaji akan mempengaruhi sifat fisik maupun kimia dari media itu sendiri yang nantinya akan sangat mempengaruhi pertumbuhan dan perkembangan tanaman. Sifat fisik dan kimia dari media yang digunakan pada penelitian ini disajikan pada Lampiran 1. Berdasarkan lampiran 1 tersebut terlihat unsur hara $\mathrm{P}$ dalam media campuran tanah dan kompos serbuk gergaji relatif lebih tinggi dibanding media tanah $100 \%$, meskipun untuk semua media kandungan unsur $\mathrm{P}$ tersebut termasuk dalam kriteria sedang, sementara untuk unsur hara lainnya relatif tidak berbeda antara media tanah $100 \%$ dan campuran tanah dengan kompos serbuk gergaji. Tingginya unsur hara $\mathrm{P}$ ini kemungkinan yang menyebabkan tingginya pertumbuhan dan perkembangan bibit mahoni di pesemaian. Unsur hara P merupakan salah satu unsur hara makro yang diperlukan bagi pertumbuhan dan perkembangan tanaman, yaitu dalam hal pembelahan sel dan perkembangan meristem (Duryea dan Landis, 1984), serta dapat merangsang pertumbuhan akar, mempercepat pembungaan dan pemasakan buah dan biji (Sarief, 1984).

Selain kandungan unsur $\mathrm{P}$ yang tinggi, kemungkinan tingginya kejenuhan basa dan rendahnya kejenuhan $\mathrm{Al}$ dalam media campuran tanah dan kompos serbuk gergaji juga menyebabkan bibit mahoni yang menggunakan media campuran tanah dan kompos serbuk gergaji 50 : 50 memiliki nilai pertambahan tinggi dan diameter yang tinggi. Kejenuhan basa yang tinggi menunjukkan bahwa media tersebut belum banyak mengalami pencucian dan merupakan media yang baik bagi pertumbuhan tanaman (Hardjowigeno, 1992). Sebaliknya nilai kejenuhan Al yang rendah pada media campuran tanah dan serbuk gergaji yang menyebabkan pertumbuhan bibit lebih tinggi. Menurut Nyakpa et al. (1988), nilai kejenuhan Al yang tinggi akan meracuni bibit sehingga pertumbuhan bibit terhambat, akar tumbuh pendek dan tebal sehingga sukar untuk menembus lapisan media dan menghambat penyerapan hara.

Aplikasi pupuk NPK pada media campuran tanah dan kompos serbuk gergaji lebih efektif dibandingkan dengan media tanah $100 \%$, karena media campuran tersebut memiliki nilai kejenihan $\mathrm{Al}$ yang rendah, sehingga unsur hara lebih mudah diserap oleh tanaman (bibit), dan akhirnya berdampak pada pertumbuhan bibit lebih baik. Hal tersebut terlihat dari hasil pengamatan (Tabel 2), terlihat bahwa pertambahan tinggi dan diameter bibit dengan media tanah $100 \%$ yang dipupuk dengan NPK sebanyak 0,5 - 1,5 g/bibit, menghasilkan nilai yang lebih rendah $(8,58-9,7 \mathrm{~cm}$ untuk pertambahan tinggi, dan 1,48 - 1,69 mm untuk 
pertambahan diameter) dibanding dengan media campuran tanah dan kompos serbuk gergaji yang dipupuk dengan dosis yang sama $(10,20$ $13,31 \mathrm{~cm}$ untuk pertambahan tinggi, dan 1,74 2,19 mm untuk pertambahan diameter). Penerapan pupuk NPK dalam upaya menghasilkan pertumbuhan bibit mahoni yang baik dan efisien disarankan menggunakan media campuran tanah dengan kompos serbuk gergaji 50:50 dan dosis pupuk NPK $1 \mathrm{~g} /$ batang. Hal ini karena pada dosis NPK $1 \mathrm{~g} /$ batang menghasilkan pertumbuhan tinggi dan diameter yang tidak berbeda nyata dibanding dengan dosis pupuk NPK $1,5 \mathrm{~g} /$ batang.

Salah satu aspek yang penting sebagai indikator kualitas semai yang dihasilkan adalah nilai Indeks Kualitas Semai (IKS). Indek Kualitas Semai merupakan suatu besaran sebagai hasil gabungan dari berbagai faktor antara lain berat kering total semai, nilai kekokohan semai dan nisbah tajuk dan akar, serta erat hubungannnya dengan kandungan unsur hara dalam tanah (Blikckehaupt, 1980, dalam Puryono dan Setyono, 1996). Menurut Roller (1977) dalam Puryono dan Setyono (1996), tanaman yang dapat tumbuh baik untuk ditanam di lapangan apabila semai tersebut mempunyai nilai indeks kualitas semai 0,09. Berdasarkan data pada Lampiran 2 nampak bahwa pada semua kombinasi perlakuan media dan dosis pupuk NPK mempunyai kualitas yang sangat baik dengan nilai antara $0.09-0.18$. Nilai IKS terendah terdapat pada bibit dengan media tanah $100 \%$ dan tanpa dipupuk, yakni sebesar 0,09. Sedangkan nilai IKS tertinggi diperoleh dari bibit dengan media campuran tanah dan kompos serbuk gergaji $70: 30$, yaitu sebesar 0,18 . Nilai IKS tidak dipengaruhi secara nyata baik oleh faktor media sapih maupun dosis pupuk NPK dan interaksi antara keduanya.

\section{KESIMPULAN}

Berdasarkan hasil dan pembahasan yang telah dikemukakan di atas, dapat diambil kesimpulan sebagai berikut :

1. Pertumbuhan bibit mahoni daun lebar $(S$. macrophylla) dipengaruhi secara nyata oleh perlakuan macam media sapih dan dosis pupuk NPK serta interaksi antara keduanya, kecuali untuk nilai Indeks Kualitas Semai (IKS).
2. Kombinasi perlakuan yang terbaik dan efisien dalam penggunaan pupuk NPK pada pembibitan mahoni adalah menggunakan media campuran tanah dengan kompos serbuk gergaji $50: 50$ pada dosis $1 \mathrm{~g} / \mathrm{bibit}$. Kombinasi perlakuan ini menghasilkan pertambahan tinggi dan diameter masingmasing sebesar $12,22 \mathrm{~cm}$ dan $2,19 \mathrm{~mm}$.

\section{DAFTAR PUSTAKA}

Duryea, M.I. dan D.T. Landis. 1984. Forest Nursery Manual. Martinius Nijhoff/ Dr W. Junk. Boston.

Hardjowigeno, S., 1992. Ilmu Tanah. PT. Mediyatama Sarana Perkasa. Jakarta.

Hendromono. 1987. Pertumbuhan dan Mutu Bibit Acacia mangium Wild, Eucalyptus deglupta Blume pada Tujuh Macam Media yang Diberi Kapur. Tesis. Fakultas Pasca Sarjana Institut Pertanian Bogor. Bogor. Tidak dipublikasikan.

Heriyanto, N.M. dan Masano. 1997. Pengaruh Media Serbuk Gergaji terhadap Pertumbuhan Semai Shorea selanica BL dan Shorea leprosula Miq. Buletin Penelitian Hutan No. 607. Pusat Penelitian dan Pengembangan Hutan dan Konservasi Alam. Bogor.

Nyakpa, M.Y., A.M. Lubis, M.A. Pulung, G. Amrah, A. Munawar, G.B. Hong, dan N. Hakim. 1988. Kesuburan Tanah. Universitas Lampung. Lampung.

Puryono, K.S. dan A, Setyono. 1996. Pengaruh Jenis Media dan Naungan serta Inokulasi Jamur Mikoriza terhadap Pertumbuhan Semai Ulin (Eusideroxylon zwageri Tet. B). Buletin Tekhnologi Reboisasi No. 5 : 9-22. Balai Teknologi Reboisasi. Palembang.

Sarief, S. 1984. Kesuburan dan Pemupukan Tanah Pertanian. Pustaka Buana Bandung Institut Teknologi Bandung. Bandung.

Widiarti, A. 1995. Pengaruh Tanaman Inang dan Medium Tumbuh terhadap Pertumbuhan Bibit Cendana (Santalum album) di Persemaian. Buletin Penelitian Hutan No. 586. Pusat Penelitian dan Pengembangan Hutan dan Konservasi Alam. Bogor. 


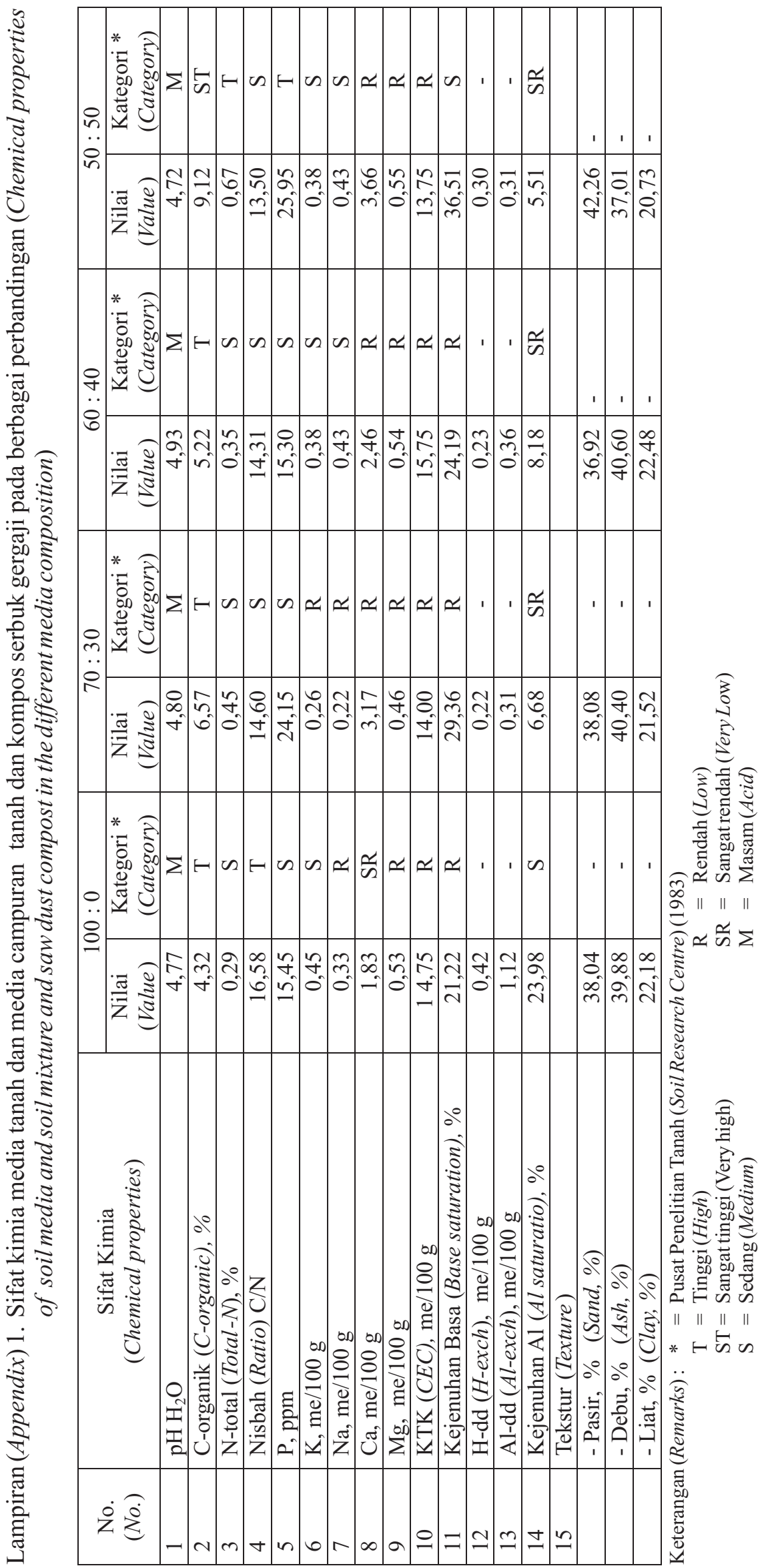


Lampiran (Appendix) 2. Nilai Indeks Kualitas Semai bibit mahoni umur 4 bulan (Quality Index Value of mahogany seedling at 4-month age)

\begin{tabular}{|c|c|c|c|c|}
\hline \multirow{2}{*}{$\begin{array}{c}\text { Dosis pupuk NPK, } \mathrm{g} / \mathrm{btg} \\
\text { (NPK Fertilizer Rate, } \mathrm{g} / \text { seedling) }\end{array}$} & \multicolumn{4}{|c|}{$\begin{array}{l}\text { Tanah : kompos serbuk gergaji } \\
\text { (Soil : Saw dust compost })\end{array}$} \\
\hline & $100: 0$ & $70: 30$ & $60: 40$ & $50: 50$ \\
\hline 0 & 0,09 & 0,13 & 0,11 & 0,14 \\
\hline 0,5 & 0,11 & 0,14 & 0,15 & 0,17 \\
\hline 1 & 0,11 & 0,18 & 0,14 & 0,13 \\
\hline 1,5 & 0,12 & 0,13 & 0,13 & 0,15 \\
\hline
\end{tabular}

